\section{Transforming the food system is the people's work: Experiential knowledge shows us the way}

\author{
Review by Branden Born *
}

The People's Knowledge Editorial Collective (Eds.). (2017). $E$ veryday $\mathrm{E}$ x perts: $\mathrm{H}$ ow People's Knowledge $\mathrm{C}$ an T ransform the $\mathrm{F}$ ood System. Coventry, UK: Coventry University. Available for free download at https:// www.coventry.ac.uk/ everyday-experts

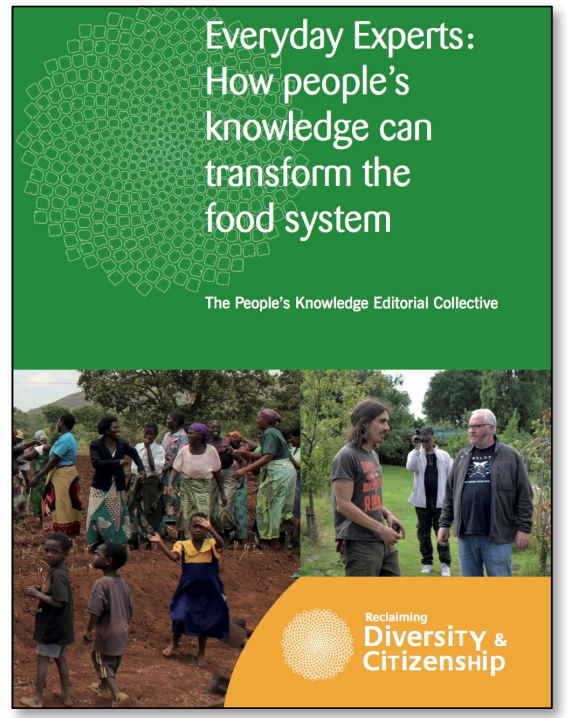

Submitted D ecember 10, 2018 / Published online March 28, 2019

Citation: Born, B. (2019). Transforming the food system is the People's work: Experiential knowledge shows us the way [Book review]. Journal of A griculture, F ood Systems, and Community D evelopment, 8(4), 229-231. https:/ / doi.org/ 10.5304/ jafscd.2019.084.019

Copyright $\odot 2019$ by the Author. Published by the Lyson Center for Civic Agriculture and Food Systems. Open access under CC-BY license.

T his volume, available online as chapters or in full, is designed to support people's participation in decision-making in their localities and around their food and food system. It showcases examples that balance efforts of people with process knowledge (e.g., academics and other professionals) with those who have experiential knowledge (i.e., lived experience). The latter are the everyday experts of the title. Their stories, projects, lessons, and challenges run through 28 chapters and demonstrate the editorial collective's interest in affirming multiple epistemologies and methods. By de-centering the professional experts, the editors fulfill their "call for the recognition and affirmation of Indigenous, local, traditional and other non-

* Branden Born is an associate professor of urban design and planning at the University of Washington. His research interests include planning process, democracy, and food systems. He can be contacted at bborn@uw.edu. mainstream knowledge systems" (p. xix). Instead of reporting knowledge simply based in science and scientism, the editors have brought together a group of author participants who share an understanding of a broader set of knowledges driven by co-production in nonhierarchical dialogue, including multiple indigenous epistemologies. If you have read, or written, about how society needs a transformation in how we go about addressing social justice and environmental sustainability or regeneration in the face of mounting global challenges, this book will be a valuable contribution to your reading list and you might find inspiration here. In fact, it would be hard not to.

The editors, and most chapter authors, would seek to disrupt the hegemonic domination of capitalist market and scientific logic in both food and knowledge systems. They seek cognitive justice, the "active valuing of different knowl- 
Journal of Agriculture, Food Systems, and Community D evelopment ISSN : 2152-0801 online

https:/ / www.foodsystemsjournal.org

edges" and critique of Western science and neoliberalism (pp. xix, xxi). In many chapters this is manifest by a decolonizing framework, explicitly rejecting top-down knowledge creation and the dispossession of people's knowledge on land, plants, and animals. This puts the communities and projects in the book up against almost unyielding forces in the global food system: past and present $\mathrm{G}$ reen Revolution schemes, and the legal, technical, and industrial model of food, agriculture, and economic production. While this seems like it might be a Sisyphean task, doomed to exhausting community members in a never-ending losing battle, the point of the book is exactly the opposite. Instead of showing futile efforts, the cases demonstrate alternatives to the current system and epistemology and the logics that drive it. In this regard, the cases represent a myriad of D avids, simultaneously facing up against an industrial food system $\mathrm{G}$ oliath. And for that reason this book is not just valuable, but important. Alternative food initiatives in the Global South and Global North are in need of inspiration, connection, and networking based on solidarity and shared interest. Cognitive justice through the recognition of many forms of knowledge necessarily suggests sharing through nonhierarchical networks of communities and organizations, and explicitly rejects knowledge hierarchies. Books like these, especially when made available for free via download, provide opportunities for community projects to discover and learn from each other regardless of location.

As to the electronic format, the authors take advantage of it in more ways than just the download access. They include active links to sources, organizations, and even videos on several platforms that detail projects such as community theater for grassroots education, agricultural techniques, and peer-to-peer learning. Reading the chapters can become non-linear due to the ease of visiting links to organizations' activities. For the most part this enriches the case studies by allowing the reader to see, literally, the places and projects being described. This seems like a contemporary and productive way for disseminating materials to food systems researchers and practitioners, allowing the subjects to speak for themselves and demonstrate in their own way the practices they want to share, and thus somewhat avoiding the expropriation of knowledge about which the editors are concerned.

The book is organized into five thematic areas: (1) Participatory research-practitioner reflections, (2) knowledge process in social movement organizations and nongovernment organizations, (3) education and critical learning processes, (4) community-university engagement, and (5) autonomous approaches to action research (knowledge processes occurring in spaces outside mainstream institutions). I found some overlap here, with many chapters including more than one of the themes. This meant that I was engaged with each section in similar ways and did not strongly identify chapters with sections. For the reader, this means that they will want to look beyond the section(s) that might interest them most and read from each part of the book.

One strength of the book is that it provides numerous examples of alternative, grassroots forms of organizing and implementing projects for social change in the food system. From reflections on top-down and bottom-up strategies to autonomous systems development, there are cases to be learned from. I knew of only a couple. The framing in the introduction is worth reading itself as a standalone chapter. The food sovereignty and community empowerment elements that run through most chapters are by now common strategies in alternative food movements and the literature that engages them.

The gap the book attempts to fill, and does so to a reasonable extent, is the examination of methods and methodologies used by social movements "to reclaim and mobilize knowledge" (p. xxvi). The editors and authors use these "knowledge strategies" to reflect on several objectives laid out in the introduction: challenging the frame of Western scientism, working collectively to produce knowledge and building solidarity between those groups doing so, developing critical understanding through education and reflection, and providing examples and analysis (pp. xxix- xxx). In large part the book is successful in most of these objectives, although the short format of the chapters does not really allow much space for in-depth 
analysis of methods and outcomes once cases are defined and explained. Many of the cases suggest they use the theory or pedagogy of Paulo Freire or Orlando Fals Borda, or some version of participatory action research. While this is apparent, the discussion of such theory in practice is often cursory and would be a fruitful topic for further explanation in those chapters, particularly where academics enlist such framing.

The strength of the book- many locations and cases- is also one of its weaknesses. It can seem repetitive and sometimes shallow. This is perhaps not unexpected; it is where a survey-style book is likely to suffer. However, perspectives on how important this is in the current example will vary by reader. In most ways the objectives are met. Organizationally, the thematic areas help structure the chapters, but the chapters are so similar in form and limited length that it feels a bit repetitious- like speed dating for alternative food networks. That said, the repetition itself is interesting because it suggests a certain amount of either autonomous or networked learning about social processes happening in many places somewhat simultaneously. Perhaps this is something to be continuously relearned: environmentally and socially, just food systems work requires participation and leadership from the people most connected or impacted by the work. Regarding the depth of treatment of the cases, those who seek a deeper understanding of practice through thorough descriptions of methods are likely to be somewhat disappointed. Also, relating to the repetitive structure of the chapters, the concluding remarks in each are often perfunctory - and almost not necessary in such short pieces. I would rather have had more description of methodological decisions or analysis.

However, because the book brings together as authors everyday experts, academics, and students and young people, and is written for a popular audience, it is appropriately read as a survey piece. It provides an overview of many locations, organizations, and efforts to improve the existing (or bringing about a new) food system while pushing back the current globalized food system. As such it is an excellent resource. Additionally, while chapter bibliographies are uneven, some provide excellent references for those interested in pursuing the themes further. Thus, the weaknesses of this book are almost inherent in the way it came about and its editorial interest in inclusion, solidarity, and demonstration. And the strengths significantly outweigh the weaknesses in this case.

I would have liked to see another chapter or two that developed some cross-cutting themes more deeply, like indigeneity and sovereignty in a modern context, or the longer-term or larger scalar implications of nonhierarchical, highly locally dependent decision-making and action. Given the richness of the many cases, it would have been nice to see if they have something to say about a practical issue within anarchistic thought: what happens when crossing scales, or at border cases when boundaries come together? This area would have been a fruitful one to advance theory with practical, everyday experience. That's not really the point of this book, though, and I realize my interests as an academic in the challenges of praxis are not really part of the books' objectives. I remain inspired by what was presented, and have a new list of projects to investigate and reading to do. 